\title{
Challenging the Leader or the Follower: Influence of Need for Emotion and Equality Violations on Emotional and Retributive Reactions in Social Dilemmas ${ }^{1}$
}

\author{
Jeroen Stouten ${ }^{2}$ \\ University of Leuven \\ Leuven, Belgium
}

\begin{abstract}
Research has shown that if equality is violated in public-good dilemmas, group members react with more anger if another group member (a follower), rather than if the leader violates equality. The present research argued that people's personalityparticularly, need for emotion-moderates group members' reactions if equality is violated by either the leader or a follower. Results revealed that group members low in need for emotion reacted with more anger and were more inclined to exclude the violator if this person was a follower, rather than the leader of the group. Group members high in need for emotion, however, reacted with more anger and wished to exclude the violator more if this person was the leader, rather than a follower.
\end{abstract}

In organizations, employees often work together in small teams in order to accomplish certain tasks, such as specific projects in work teams. In such situations, there is often a conflict between the individual and collective interests. That is, for individual group members, it is more profitable not to invest much in the group and still be able to take advantage of the group's collective efforts. However, if all group members make a similar decision, the group's tasks are likely to fail and everyone will be worse off. Such a situation is often referred to as a social dilemma, and more specifically, a step-level public-good dilemma (Komorita \& Parks, 1994). In step-level public-good dilemmas, sufficient investments must be made in order to provide the public good.

In these public-good situations, people generally make use of certain fairness principles, such as the equality rule (e.g., Deutsch, 1975). The equality rule holds that when everyone expects to earn an equal share from the public good, group members are also expected to contribute equally (Van Dijk \& Wilke, 1995, 2000). Equality has been shown to be strongly related to

${ }^{1}$ This work was supported by Grant \#GOA/05/04 from the Research Fund of the Katholieke Universiteit Leuven.

${ }^{2}$ Correspondence concerning this article should be addressed to Jeroen Stouten, Department of Psychology, University of Leuven, Tiensestraat 102, 3000 Leuven, Belgium. E-mail: jeroen.stouten@psy.kuleuven.be

Journal of Applied Social Psychology, 2008, 38, 5, pp. 1378-1394.

(C) 2008 Copyright the Authors

Journal compilation (C) 2008 Blackwell Publishing, Inc. 
justice issues, as it is perceived to be fair to contribute an equal share (e.g., Van Dijk \& Wilke, 1995). Moreover, when this equality principle is violated by one of the group members (by contributing less than an equal share to the public good), this is perceived as unjust and may lead to strong emotions of anger (Stouten, 2005). Previous research has also shown that the angerprovoking potential of equality violations depends on the position of the violator in the group. If equality was violated (which also led to failure of the group) by the leader of the group, group members exhibited less negative reactions than if a follower violated equality (Stouten \& Tripp, in press). Hence, the role of the violator in the group is of importance for understanding the emergence of people's reactions of anger in situations in which the fairness rule of equality is violated.

Previous research has suggested, however, that large individual differences exist in the tendency to react with anger to certain events (e.g., George, 1990). Knowledge about which personality factors determine these differences can be important in determining which group members are prone to anger. To date, however, little research has taken into account the influence of group members' individual differences in anger as a result of distributively unjust situations, such as equality violations. In addition, the research that did look into individual differences in distributive justice has focused mostly on the Big Five factors (Kozlowski \& Bell, 2003). Recently, however, researchers have suggested that the Big Five factors may be too broad, and that it may be more useful to study specific individual differences (e.g., Schneider, Hough, \& Dunnette, 1996).

The present research focuses on the personality trait need for emotion, which is specifically important for people's emotional reactions and which is also known for its relations with adherence to fairness principles (e.g., Maio \& Esses, 2001; Raman, Chattopadhyay, \& Hoyer, 1995). It is argued that people who desire to experience emotions are more analytical and feel more responsible. Therefore, need for emotion may be related to emotions of anger in a situation in which equality is violated. More specifically, anger will be instigated especially if the leader of the group violates equality, because the leader is expected to behave fairly.

\section{Equality and Leadership}

As described previously, the equality rule is a pervasive coordination rule in public-good dilemmas. If another group member violates such an important justice rule (by contributing less than an equal share), this leads to emotions of anger (Stouten, 2005). In such a situation, which calls to mind a great deal of uncertainty for the group, the appointment of a leader has been 
shown to have a positive influence on the group as a whole (De Cremer, 2002; Messick et al., 1983; Rutte \& Wilke, 1984).

After all, leaders are expected to act fairly for the group's welfare (Messick et al., 1983; Rutte \& Wilke, 1984). In fact, group leaders are expected to act in a responsible and just manner serving the group's interests (Samuelson \& Messick, 1995). Yet, sometimes the leader may also act so much in self-interest as to take a greater share of the rewards by contributing less than other members (De Cremer, 2003; De Cremer \& Van Dijk, 2005; Samuelson \& Allison, 1994).

In fact, leaders may even feel entitled to have more benefits (De Cremer \& Van Dijk, 2005). However, research has shown not only that leaders feel entitled to more by contributing less to the public good, but it appears that followers also perceive the leader to be entitled to earn more. For example, a recent study showed that group members reacted with less anger if a leader, rather than a follower violated the equality rule in a public-good dilemma situation (Stouten \& Tripp, in press). More specifically, it was shown that if the leader, rather than a follower violated the equality rule, group members considered this less of a norm violation and were more likely to forgive the violator. This suggests that followers agree that leaders should be able to have more, even though this would be the result of violating socially accepted rules (e.g., equality). The present research, however, argues that depending on people's individual differences, these results may not account for all group members' reactions.

\section{The Role of Individual Differences}

Schmitt and Dörfel (1999) argued that "individuals differ in their need for justice and in the extent to which they consider justice to be a central human value" (p. 444). Hence, people may perceive justice in a different way and react differently to injustice events, depending on their personality characteristics (Edney, 1980; Mitchell, Tetlock, Mellers, \& Ordóñez, 1993) because they may appraise the situation in another way (e.g., Roseman \& Smith, 2001).

Research has shown that people's reactions to fairness judgments are a complex interaction between the description of the situation and individual differences (e.g., Colquitt, Scott, Judge, \& Shaw, 2006; Skarlicki, Folger, \& Tesluk, 1999). The inclusion of individual differences by using a Personality $\times$ Situation perspective, therefore, may contribute to a more complete picture of people's emotional reactions to unfair situations, such as equality violations (e.g., Leventhal, Karuza, \& Fry, 1980). Individual differences may be of particular importance in understanding group members' angry reactions in 
situations in which the equality rule is violated. Indeed, people may react with less or more anger in a situation in which the equality rule is violated, depending on whether the violator is another group member or the leader of the group.

The role of individual differences has received renewed interest in the context of work-related affect. Research has demonstrated convincingly that people differ in the extent to which they perceive situations and in the emotional reactions that follow from these perceptions (e.g., Brief, Burke, George, Robinson, \& Webster, 1988; Cropanzano, James, \& Citera, 1993; George, 1990).

A personality trait that is known to be specifically related to the experience of emotions and its relation to being sensitive to the adherence of moral principles is need for emotion (Maio \& Esses, 2001; Raman et al., 1995). Need for emotion is related to seeking out or avoiding situations that are emotional, which may influence their perceptions of a situation in which fairness is violated. That is, people who are high in need for emotion desire to experience and understand the emotions of oneself and others, and use these emotional experiences to influence their judgments and decisions. They also tend to be more motivated to analyze situations and emotional experiences (Maio \& Esses, 2001). People who are inclined to analyze specific situations also have been shown to be more politically involved and active with regard to policy issues (Bizer et al., 2004). Finally, need for emotion is also related to extraversion, openness, agreeableness, and conscientiousness; all characteristics of people who can be described as resilient, as they generally can be portrayed as having a greater impact on their environment and greater social responsibility (see also Jensen-Campbell \& Graziano, 2001; Van Hiel, Mervielde, \& De Fruyt, 2006).

Hence, people high in need for emotion are characterized by strong affective experiences, being more motivated to analyze situations, and also feel more involved because of feelings of responsibility. Because of this, it is argued that people's need for emotion may be especially related to situations in which the justice principle of equality is violated by the responsibility of another group member. More specifically, people high in need for emotion may be more sensitive to such fairness violations. Therefore, these people may be specifically opposed to a violation of equality by the leader of the group as they consider a leader violating such a fairness principle as inappropriate. They may reason that a leader may be entitled to earn more, but may also reason that this does not entail violating fairness norms. Such a violation reflects the leader acting on his entitlement by exhibiting selfinterested behavior. Hence, people high in need for emotion may be strongly emotionally upset and consider it inappropriate for leaders to violate fairness rules. Hence, people high in need for emotion may react with more anger if 
equality is violated and the violator is known to be the leader, rather than the follower of the group, because the leader exploits his role at the expense of the whole group (because the group failed in providing the public good).

In contrast, people who are low in need for emotion are less evaluative and emotional and, therefore, may be less concerned with the leader violating equality because they consider the leader to be entitled to earn more. They may reason that because the leader was appointed, it would be more legitimate if a leader, rather than a follower would benefit more and, therefore, they would react with more anger if a follower (rather than a leader) violated equality.

In the present research, participants were introduced to a public-good dilemma situation in which they and three other group members (ostensibly) were present in the laboratory. Before participants engaged in the decision task, it was said that because in many groups there is a leader, a leader would first be appointed among the participants. This was done by having the participants complete a management questionnaire in which the group member who scored best on the questionnaire became the leader of the group. This procedure was adapted from De Cremer and Van Dijk (2005) and was perceived to be a legitimate procedure for appointing a leader.

Next, the participants decided on their investment in the group's public good. It was said that the group had failed in investing sufficiently. It appeared that one group member had failed to contribute an equal share, and this had led to the group's failure. This procedure was adapted from Stouten (2005). It is known to be perceived as unfair and elicits strong reactions of anger. In the leader condition, participants learned that the violator of equality was the leader of the group; whereas in the follower condition, participants learned that the violator was another group member (i.e., a follower, and not the group's leader).

The primary focus in the present research is on the emotion of anger. In general, emotions can be described as psychological responses or states that emerge in response to a particular evaluation or appraisal of persons or events (e.g., Frijda, 1986). More specifically, anger may be instigated by an unpleasant event for which another person is responsible (Smith \& Ellsworth, 1985). In addition, anger may emerge when accepted social norms are violated or when there is disapproval of someone's blameworthy action (Shaver, 1985). Moreover, it has been suggested that emotions are closely related to issues of morality and fairness (Averill, 1983; Leventhal et al., 1980), as people evaluate certain conditions according to their personal goals and values, and that from these evaluations, emotional reactions may arise. Situations perceived as unjust are very likely to elicit anger from the person who was treated unfairly (Aquino, Lewis, \& Bradfield, 1999; Mikula, Scherer, \& Athenstaedt, 1998; Weiss, Suckow, \& Cropanzano, 1999). 
In addition, situations that are perceived as unjust also are important instigators of counterproductive behavior (Bies \& Tripp, 1996; Skarlicki et al., 1999). It has been suggested also that these situations can be instigators of self-interested actions to take revenge (i.e., retributive actions; Bond \& Venus, 1991; Bourgeois \& Leary, 2001; Goldberg, Lerner, \& Tetlock, 1999; Smith, 2002) and to threaten the further existence of the group by excluding some members from further participation (e.g., Ayduk, Downey, Testa, \& Yen, 1999). Therefore, in the present research, it is argued that excluding a group member who violated equality may be a specific type of retributive behavior that group members may decide to take, as such an action communicates that the violator is unwanted by the others and is socially punished (Kerr, 1999). That is, similar to anger, it is expected that people who are high in need for emotion may be more willing to exclude the violator of the group if this person is the leader, rather than a follower. However, people who are low in need for emotion are expected to be more willing to exclude the violator from the group if this person is a follower, rather than the leader of the group.

\section{Method}

\section{Participants and Design}

Participants were 48 undergraduate students who were paid 7 Euro ( $\$ 10.26$ US) for their participation. The participants were assigned randomly to the leadership conditions.

\section{Procedure}

Upon entering the laboratory, participants were seated in separate cubicles containing a chair, a table, and a computer. All of the instructions were presented on a computer screen. Participants were informed that they were part of a 4-person group that would play several games, and that they (supposedly) would be able to interact with one another via the computer. In reality, the computers were not connected with each other. Group members were referred to as Group Member 1 to 4 (in reality, all participants were told that they were Group Member 3).

Public-good dilemma. The public-good dilemma was then introduced. Participants learned that they possessed a personal endowment of 100 chips (each chip $=0.05$ Euro or $\$ 0.07$ US), which, if they wished to do so, they could contribute. If the group managed to reach a given threshold of 200 
chips, then the group would receive a bonus, which would be divided equally among the four group members. Hence, when the threshold of 200 chips was reached, the group would earn a bonus of 400 chips (i.e., 100 chips for each of the group members).

After explaining the situation, some comprehension questions were asked in order to check whether participants understood the situation. All of the participants answered these questions correctly. Then, participants could decide which amount they wished to contribute to the public good. After their decision, participants learned about the other members' contributions. First, it was said that the group did not contribute a sufficient number of chips to reach the threshold. Then, the exact number of chips each group member contributed was shown. Participants learned that two group members contributed an equal share (i.e., 50 chips), while another group member (Group Member 2) violated the equal share by contributing only 10 chips (this procedure was taken from Stouten, 2005).

Leadership manipulation. Before participants could decide about their contribution to the public good, the leadership manipulation was introduced. Participants were told that in groups, there often is a leader to coordinate group decisions. Therefore, in this situation, it was determined that a leader would be appointed. To appoint a leader in a legitimate manner, the person who scored highest on a questionnaire assessing leadership qualities would be appointed as leader of the group. Participants completed the 26-item Management Assessment Inventory (MAI). The MAI consists of items such as "Leadership is a matter of influencing others" and "A leader should be able to command respect."

After a short interval, participants received bogus feedback about the results of the inventory. Participants in the leadership condition learned that for the remainder of the experiment, Group Member 2 (i.e., the violator of equality) would perform the role of leader in the group and that the participant would be a follower. Participants in the follower condition learned that Group Member 4 would be the leader and that the participant would be a follower. Then, participants were asked a few questions concerning their roles in the group (for a similar procedure, see De Cremer \& Van Dijk, 2005). After checking for their roles in the group, it appeared that all participants correctly remembered their roles in the group.

Need for emotion. Need for emotion was assessed using Raman et al.'s (1995) measure. The measure consists of 12 items and has been shown to be strongly related to the measure of need for affect (Maio \& Esses, 2001). Sample items are "Experiencing strong emotions is not something I enjoy very much," "I prefer to keep my feelings under check," and "I prefer to ignore the emotional aspects of situations, rather than getting involved in them." 
Dependent measures. All of the questions were answered on a 7-point scale ranging from 1 (not at all) to 7 (very much so). Before the social dilemma game was introduced, participants were led to believe that they were first going to participate in another unrelated study. They were asked several questions including how they felt in this situation using the terms angry, irritation, frustrated, rage, and hostile in order to assess emotions of anger. Other filler emotions were also assessed, such as satisfied, fearful, relieved, and surprised.

Participants then learned that one group member had violated the equality rule, and they were asked to respond to the same emotions of anger and the same filler emotions as before. Further, a one-item measure of group members' willingness to exclude was assessed by asking participants the extent to which they wanted the group member who had violated the equality rule to be excluded from the group. Finally, participants were debriefed, thanked, and paid.

\section{Results}

Anger

In order to correct for participants' prior mood, difference scores for the anger emotions were calculated by subtracting the anger emotions before the start of the experiment from the anger emotions that were assessed afterward. Because the different anger emotions were shown to be highly reliable (Cronbach's $\alpha_{\text {before }}=.81$; Cronbach's $\left.\alpha_{\text {after }}=.90\right)$, one combined anger score was computed $(M=1.30, S D=1.57)$.

The independent variables of need for emotion and leadership were then centered for regression analyses (Aiken \& West, 1991). A regression analysis of need for emotion, leadership, and the interaction term on anger reveals a significant interaction $(\beta=-.51, p=.001$; see Figure 1$)$. Simple-slopes analyses show that people low in need for emotion reacted with more anger if a follower, rather than a leader violated equality $(\beta=.57, p<.005)$. In contrast, people high in need for emotion reacted with more anger if a leader, rather than a follower violated equality $(\beta=-.47, p<.05)$.

\section{Excluding the Violator}

A regression analysis on the extent to which participants wanted to exclude the violator from further participation in the group $(M=3.56$, $S D=1.53)$ shows a significant interaction effect $(\beta=-.40, p<.01$; see 


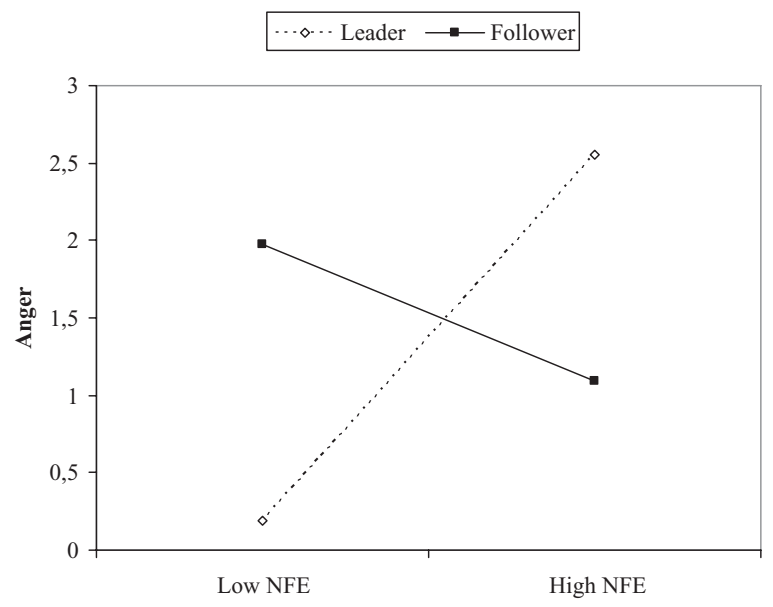

Figure 1. Difference in anger after a violation of equality by the leader or follower as a function of need for emotion (NFE).

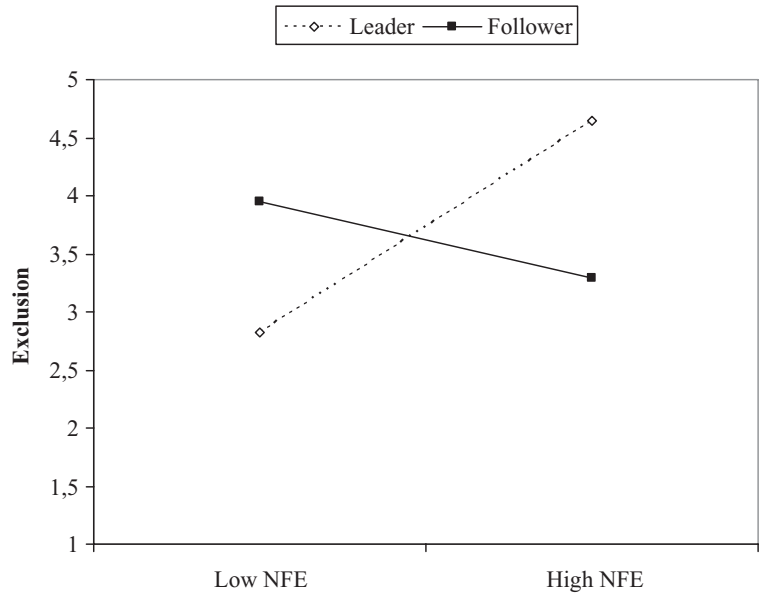

Figure 2. Willingness to exclude the violator after a violation of equality by the leader or follower as a function of need for emotion (NFE).

Figure 2). Simple-slopes analyses show that, although slightly marginally significant, group members low in need for emotion were more inclined to exclude the violator if a follower, rather than a leader violated equality ( $\beta=.37, p=.07)$. In contrast, group members high in need for emotion 
wanted to exclude the violator more if a leader, rather than a follower violated equality $(\beta=-.45, p<.05)$.

\section{Discussion}

Violating an important coordination and fairness rule (e.g., equality) in public-good dilemma situations results in negative reactions by the other group members. Contributing less than an equal share has been shown to elicit emotional reactions; more specifically, anger. In such situations, groups often have a leader to resolve conflicts and who is able to facilitate the group's performance. Previous research, however, not only has shown that leaders find themselves entitled to more (thereby exploiting the group) in social dilemmas, but group members also react with less anger if a leader, rather than a follower violates the equality rule (De Cremer \& Van Dijk, 2005; Stouten \& Tripp, in press).

People differ greatly in the extent to which they want to experience emotions. The present research shows that group members' reactions to a leader or a follower who violates equality is dependent on people's personality characteristics.

More specifically, the present research focused on an individual-difference variable that is related to the experience of emotions and the need to evaluate social situations; that is, need for emotion (Raman et al., 1995). The results show a disordinal (or crossover) interaction between need for emotion and leadership: People who were low in need for emotion reacted with less anger if a leader, rather than a follower violated equality. In addition, they were also less inclined to take retributive actions by being less disposed to exclude the violator from the group if this person was the leader, rather than a follower. These results line up with the findings described previously: Leaders are entitled to more and will be evaluated less negatively than will followers if they violate equality rules. In contrast, people who were high in need for emotion reacted with more anger if a leader, rather than a follower violated equality. Also, they were more inclined to exclude the violator of equality if the violator was the leader of the group, rather than the follower.

Hence, people who are high in need for emotion consider the act of violating equality rules inappropriate and are motivated to take action in order to make the violator get his "just desserts." People who are high in need for emotion analyze the situation more intensively. That is, need for emotion relates to such personality traits as extraversion, agreeableness, and conscientiousness, making them feel responsible to follow regulations and moral principles. These people are often described as highly resilient (Van Hiel et al., 2006), therefore being more sensitive to normative violations, such as a 
leader acting on his entitlement by violating fairness rules. They may consider the leader earning more to be legitimate, but the leader crossed the line by violating fairness rules at the expense of the group. People who are low in need for emotion are less concerned with following regulations or responsibilities; therefore, they may consider the leader to be entitled to earn more, even if this would imply violating fairness norms that damage the group.

The present results also add to research on the individual-difference factor need for emotion by showing that people high in need for emotion not only analyze the situation more, but also that they are sensitive to norm violations. This corresponds to the finding that need for emotion relates to need for cognition (Maio \& Esses, 2001). People who like to experience emotions use these emotions to guide their perceptions and judgments, and are more likely to think about the ongoing situation. This suggests that people high in need for emotion are indeed more sensitive to issues concerning personal responsibility and fairness issues (see also Jensen-Campbell \& Graziano, 2001; Van Hiel et al., 2006) because they are more cognitively engaged to analyze the situation. Moreover, people high in need for emotion are also willing to put this into practice; for example, by being involved in policy issues (Bizer et al., 2004). The present research is among the first to examine the role of need for emotion in social interactions and its role in fairness situations. However, more research is needed to look into how and why need for emotion is involved in adherence and opposition to fairness and norms.

The results discussed previously show that taking into account individual differences is important in creating a completer picture of how people react in a situation in which a group member (i.e., leader or follower) violates equality. Research has demonstrated convincingly that people differ in the extent to which they perceive situations and in the emotional reactions that follow from these perceptions (e.g., Brief et al., 1988; Cropanzano et al., 1993; George, 1990). Moreover, people's reactions are often dependent on the combined result of individual differences and the situation with which they are confronted (Skarlicki et al., 1999; Van Lange, De Cremer, Van Dijk, \& Van Vugt, 2007). Therefore, the present research focused on a Person $\times$ Situation approach (Snyder \& Cantor, 1998) and was able to show that individual differences (i.e., person) are indeed important in describing people's anger and retributive reactions to violations of equality, depending on the role of the violator in the group (i.e., situation).

Taking personality influences into account may actually improve one's understanding of the functioning of small-work groups and larger organizations. A better understanding of how certain people will react (emotionally and behaviorally) in a certain situation is essential for a conception of social interactions. That is, individuals may differ greatly in the extent to which their affective and behavioral reactions are aroused, depending on the specific 
circumstances of the situation as could be seen from the disordinal interactions in the present study.

To date, research on mixed motives (e.g., social dilemmas) has paid little attention to emotions (particularly anger), despite the fact that the recent literature has specifically outlined the importance of emotions in conflict situations (Hertel, 1999; Knapp \& Clark, 1991; Loewenstein \& Lerner, 2002). Moreover, the inclusion of individual differences in this line of research has only recently received attention (e.g., Scherer, 1999). The present study adds to this line of research by showing that individual differences and the specific instances of the situation (e.g., the role of the alleged violator) plays an important role in the emergence of people's emotional reactions. More specifically, the present research focused on the discrete emotion of anger. Indeed, it has been argued recently that studying discrete emotions adds to a better understanding of the emergence of specific emotions in a given situation, in contrast to the study of more global emotional dimensions (e.g., Roseman, 1991; Weiss et al., 1999). This practice ensures that more specific predictions can be made, apart from saying that someone reacts negatively or positively in a given situation.

In addition to reactions of anger, the present research also focused on retributive behavior; that is, the choice of excluding the one who was responsible for the equality violation and, hence, the failure of the entire group. For example, the organizational literature has shown that injustice is the prime trigger of workplace revenge (Tripp, Bies, \& Aquino, 2007). If organizations (including their leadership) are not perceived as fair, then employees are much more likely to retaliate (Bies \& Tripp, 1996; Skarlicki et al., 1999), such as by stealing office supplies (Greenberg, 1990) and engaging in variety of other behaviors that undermine organizational leadership, including loafing, following orders to the letter instead of to the spirit, quitting without notice (Bies \& Tripp, 1996; Jones \& Skarlicki, 2003), and sabotage (Ambrose, Seabright \& Schminke, 2002).

The present research focused on the exclusion of group members from the group. Such actions are detrimental for small groups because they result in the problem that the group must attain the public good with fewer group members (see Van Vugt, Jepson, Hart, \& De Cremer, 2004). Nevertheless, the results show that group members were indeed inclined to take such actions, even though this would imply that the group must work harder. Interestingly, recent research has shown that excluding a group member results in the group member taking revenge on the group (e.g., Twenge, Baumeister, Tice, $\&$ Stucke, 2001). The present results suggest that anger may instigate excluding a transgressing group member, but this group member may in turn take revenge. Such a situation may easily end up in a conflict circle, which is disastrous for the group's functioning. 
In conclusion, the present research creates new insights by showing that specific individual differences influence anger and retributive reactions upon violations of equality in social dilemmas, depending on the specific status of the violator. Need for emotion has been shown to play an important role in how people react to violations of equality by a leader or a follower. Hence, taking into account people's differences in personality is an essential avenue for understanding how and why people react and behave in social interactions.

\section{References}

Aiken, L. S., \& West, S. G. (1991). Multiple regression: Testing and interpreting interactions. New York: Sage.

Ambrose, M. L., Seabright, M. A., \& Schminke, M. (2002). Sabotage in the workplace: The role of organizational injustice. Organizational Behavior and Human Decision Processes, 89, 947-965.

Aquino, K., Lewis, M. U., \& Bradfield, M. (1999). Justice constructs, negative affectivity, and employee deviance: A proposed model and empirical test. Journal of Organizational Behavior, 20, 1073-1091.

Averill, J. R. (1983). Studies on anger and aggression: Implications for theories of emotion. American Psychologist, 38, 1145-1160.

Ayduk, O., Downey, G., Testa, A., \& Yen, Y. (1999). Does rejection elicit hostility in rejection-sensitive women? Social Cognition, 17, 245-271.

Bies, R. J., \& Tripp, T. M. (1996). Beyond distrust: "Getting even" and the need for revenge. In R. Kramer \& T. R. Tyler (Eds.), Trust in organizations: Frontiers in theory and research (pp. 246-260). Newbury Park, CA: Sage.

Bizer, G. Y., Krosnick, J. A., Holbrook, A. L., Wheeler, S. C., Rucker, D. D., \& Petty, R. E. (2004). The impact of personality on cognitive, behavioral, and affective political processes: The effects of need to evaluate. Journal of Personality, 72, 995-1027.

Bond, M. H., \& Venus, C. K. (1991). Resistance to group or personal insults in an in-group or out-group context. International Journal of Psychology, 26, 83-94.

Bourgeois, K. S., \& Leary, M. R. (2001). Coping with rejection: Derogating those who choose us last. Motivation and Emotion, 25, 101-111.

Brief, A. P., Burke, M. J., George, J. M., Robinson, B., \& Webster, J. (1988). Should negative affectivity remain an unmeasured variable in the study of job stress? Journal of Applied Psychology, 73, 193-198.

Colquitt, J. A., Scott, B. A., Judge, T. A., \& Shaw, J. C. (2006). Justice and personality: Using integrative theories to derive moderators of justice 
effects. Organizational Behavior and Human Decision Processes, 100, 110127.

Cropanzano, R., James, K., \& Citera, M. A. (1993). A goal hierarchy model of personality, motivation, and leadership. In L. L. Cummings \& B. M. Staw (Eds.), Research in organizational behavior (Vol. 15, pp. 267-322). Greenwich, CT: JAI Press.

De Cremer, D. (2002). Charismatic leadership and cooperation in social dilemmas: A matter of transforming motives? Journal of Applied Social Psychology, 32, 997-1016.

De Cremer, D. (2003). How self-conception may lead to inequality: Effects of hierarchical roles on the equality rule in organizational resource-sharing tasks. Group and Organization Management, 28, 282-302.

De Cremer, D., \& Van Dijk, E. (2005). When and why leaders put themselves first? Leader behavior in resource allocations as a function of feeling entitled. European Journal of Social Psychology, 35, 553-563.

Deutsch, M. (1975). Equity, equality, and need: What determines which value will be used as the basis of distributive justice? Journal of Social Issues, 31, 137-149.

Edney, J. J. (1980). The commons problem: Alternative perspectives. American Psychologist, 35, 131-150.

Frijda, N. H. (1986). The emotions. Cambridge, UK: Cambridge University Press.

George, J. M. (1990). Personality, affect, and behavior in groups. Journal of Applied Psychology, 75, 107-116.

Goldberg, J. H., Lerner, J. S., \& Tetlock, P. E. (1999). Rage and reason: The psychology of the intuitive prosecutor. European Journal of Social Psychology, 29, 781-795.

Greenberg, J. (1990). Employee theft as a reaction to underpayment inequity: The hidden costs of pay cuts. Journal of Applied Psychology, 75, 561-568. Hertel, G. (1999). Mood effects in social dilemmas: What we know so far. In M. Foddy \& M. Smithson (Eds.), Resolving social dilemmas: Dynamic, structural, and intergroup aspects (pp. 227-243). Philadelphia: Taylor \& Francis.

Jensen-Campbell, L. A., \& Graziano, W. G. (2001). Agreeableness as a moderator of interpersonal conflict. Journal of Personality, 69, 323-362.

Jones, D. A., \& Skarlicki, D. P. (2003). The relationship between perceptions of fairness and voluntary turnover among retail employees. Journal of Applied Social Psychology, 33, 1226-1243.

Kerr, N. L. (1999). Anonymity and social control in social dilemmas. In M. Foddy \& M. Smithson (Eds.), Resolving social dilemmas: Dynamic, structural, and intergroup aspects (pp. 103-119). Philadelphia: Taylor \& Francis. 
Knapp, A., \& Clark, M. S. (1991). Some detrimental effects of negative mood on individuals' ability to solve resource dilemmas. Personality and Social Psychology Bulletin, 17, 678-688.

Komorita, S. S., \& Parks, C. D. (1994). Social dilemmas. Dubuque, IA: Brown \& Benchmark.

Kozlowski, S., \& Bell, B. S. (2003). Work groups and teams in organizations. In W. C. Borman, D. R. Ilgen, \& R. J. Klimoski (Eds.), Handbook of psychology: Industrial and organizational psychology (Vol. 12, pp. 333375). London: Wiley.

Leventhal, G. S., Karuza, J., Jr., \& Fry, W. R. (1980). Beyond fairness: A theory of allocation preferences. In G. Mikula (Ed.), Justice and social interaction (pp. 167-218). New York: Springer-Verlag.

Loewenstein, G. F., \& Lerner, J. S. (2002). The role of affect in decision making. In R. J. Davidson, K. R. Scherer, \& H. H. Goldsmith (Eds.), The handbook of affective sciences (pp. 619-642). Oxford, UK: Oxford University Press.

Maio, G. R., \& Esses, V. M. (2001). The need for affect: Individual differences in the motivation to approach or avoid emotions. Journal of Personality, 69, 583-615.

Messick, D. M., Wilke, H., Brewer, M. B., Kramer, R. M., Zemke, P. E., \& Lui, L. (1983). Individual adaptations and structural change as solutions to social dilemmas. Journal of Personality and Social Psychology, 44, 294-309.

Mikula, G., Scherer, K. R., \& Athenstaedt, U. (1998). The role of injustice in the elicitation of differential emotional reactions. Personality and Social Psychology Bulletin, 24, 769-783.

Mitchell, G., Tetlock, P. E., Mellers, B. A., \& Ordóñez, L. D. (1993). Judgments of social justice: Compromises between equality and efficiency. Journal of Personality and Social Psychology, 65, 629-639.

Raman, N. V., Chattopadhyay, P., \& Hoyer, W. D. (1995). Do consumers seek emotional situations? The Need for Emotion scale. Advances in Consumer Research, 22, 537-542.

Roseman, I. J. (1991). Appraisal determinants of discrete emotions. Cognition and Emotion, 5, 161-200.

Roseman, I. J., \& Smith, C. A. (2001). Appraisal theory: Overview, assumptions, varieties, controversies. In K. R. Scherer, A. Schorr, \& T. Johnstone (Eds.), Appraisal processes in emotion: Theory, methods, research (pp. 3-19). New York: Oxford University Press.

Rutte, C. G., \& Wilke, H. A. (1984). Social dilemmas and leadership. European Journal of Social Psychology, 14, 105-121.

Samuelson, C. D., \& Allison, S. T. (1994). Cognitive factors affecting the use of social decision heuristics in resource-sharing tasks. Organizational Behavior and Human Decision Processes, 58, 1-27. 
Samuelson, C. D., \& Messick, D. M. (1995). When do people want to change the rules for allocating shared resources? In D. A. Schroeder (Ed.), Social dilemmas: Perspectives on individuals and groups (pp. 143-162). Westport, CT: Praeger.

Scherer, K. R. (1999). Appraisal theory. In T. Dalgleish \& M. J. Power (Eds.), Handbook of cognition and emotion (pp. 637-663). Chichester, UK: John Wiley \& Sons.

Schmitt, M., \& Dörfel, M. (1999). Procedural injustice at work, justice sensitivity, job satisfaction, and psychosomatic well-being. European Journal of Social Psychology, 29, 443-453.

Schneider, R. J., Hough, L. M., \& Dunnette, M. D. (1996). Broadsided by broad traits: How to sink science in five dimensions or less. Journal of Organizational Behavior, 17, 639-655.

Shaver, K. G. (1985). The attribution of blame: Causality, responsibility, and blameworthiness. New York: Springer-Verlag.

Skarlicki, D. P., Folger, R., \& Tesluk, P. (1999). Personality as a moderator in the relationship between fairness and retaliation. Academy of Management Review, 42, 100-108.

Smith, C. A., \& Ellsworth, P. C. (1985). Patterns of cognitive appraisal in emotion. Journal of Personality and Social Psychology, 48, 813-838.

Smith, H. J. (2002). Thinking about deservingness. Social Justice Research, $15,409-422$.

Snyder, M., \& Cantor, N. (1998). Understanding personality and social behavior: A functionalist strategy. In D. T. Gilbert, S. T. Fiske, \& G. Lindzey (Eds.), The handbook of social psychology (Vol. 1, 4 ${ }^{\text {th }}$ ed., pp. 635-679). Boston: McGraw-Hill.

Stouten, J. (2005). Virtue summons the fury: Coordination rules and fairness in social dilemmas. Unpublished doctoral dissertation, Tilburg University.

Stouten, J., \& Tripp, T. M. (in press). Claiming more than equality: Should leaders ask for forgiveness? Leadership Quarterly.

Tripp, T. M., Bies, R. J., \& Aquino, K. (2007). A vigilante model of justice: Revenge, reconciliation, forgiveness, and avoidance. Social Justice Research, 19, 10-34.

Twenge, J. M., Baumeister, R. F., Tice, D. M., \& Stucke, T. S. (2001). If you can't join them, beat them: Effects of social exclusion on aggressive behavior. Journal of Personality and Social Psychology, 81, 1058-1069.

Van Dijk, E., \& Wilke, H. (1995). Coordination rules in asymmetric social dilemmas: A comparison between public good dilemmas and resource dilemmas. Journal of Experimental Social Psychology, 31, 1-27.

Van Dijk, E., \& Wilke, H. (2000). Decision-induced focusing in social dilemmas: Give-some, keep-some, take-some, and leave-some dilemmas. Journal of Personality and Social Psychology, 78, 92-104. 
Van Hiel, A., Mervielde, I., \& De Fruyt, F. (2006). Stagnation and generativity: Structure, validity, and differential relationships with adaptive and maladaptive personality. Journal of Personality, 74, 543-574.

Van Lange, P. A. M., De Cremer, D., Van Dijk, E., \& Van Vugt, M. (2007). Self-interest and beyond: Basic principles of social interaction. In E. T. Higgins \& A. W. Kruglanski (Eds.), Social psychology: Handbook of basic principles (pp. 540-561). New York: Guilford.

Van Vugt, M., Jepson, S. F., Hart, C. M., \& De Cremer, D. (2004). Autocratic leadership in social dilemmas: A threat to group stability. Journal of Experimental Social Psychology, 40, 1-13.

Weiss, H. M., Suckow, K., \& Cropanzano, R. (1999). Effects of justice conditions on discrete emotions. Journal of Applied Psychology, 84, 786794. 